\title{
A clinical teaching guide for psychiatric mental health nursing: a qualitative outcome analysis project
}

\author{
S. MELROSE PhD RN \\ Instructor, Master of Health Studies Program, Centre for Health Studies, Athabasca University, Athabasca, Alberta, \\ Canada and Adjunct Assistant Professor, Faculty of Nursing, University of Alberta, Edmonton, Alberta, Canada
}

Correspondence:

S. Melrose

136 Hawkview Manor Circle N.W.

Calgary, Alberta

Canada T3G $2 Z 8$

E-mail:melrose@nucleus.com
MELROSE S. (2002) Journal of Psychiatric and Mental Health Nursing 9, 381-389

\section{A clinical teaching guide for psychiatric mental health nusing: a qualitative outcome analysis project}

\begin{abstract}
Limited curriculum enhancement resources are available to psychiatric nurse educators. This article provides a clinical teaching guide for novice instructors teaching an introductory psychiatric nursing course. The investigation is grounded in a constructivist theoretical framework and extends a previous case study project that explored how students learn during a mental health practicum (Melrose 1998, Melrose \& Shapiro 1999). The guide was tested and modified by applying a qualitative outcome analysis methodology. Insight into interpreting student behaviour and providing appropriate and stage-specific teaching tools is revealed. Theoretical components, assessment questions for teachers, student behavioural signs and teaching strategies are identified and discussed to describe significant features in creating personally meaningful learning experiences.
\end{abstract}

Keywords: psychiatric teaching guide, qualitative outcome analysis

Accepted for publication: 22 June 2001

\section{Introduction}

With the rapid and complex changes occurring in both health care and nursing education, student Registered Nurses and their clinical instructors face unprecedented challenges in psychiatric practice environments. Few mental health agencies today have escaped cutbacks, downsizing and re-structured provision of services. In nursing education, revolutionary curricular changes have occurred in response to delivering programmes of study through colleges and universities rather than hospital-based schools. Research related to clinical teaching in mental health is limited and further study is essential in order to develop contemporary teaching approaches that invite students to construct personally meaningful knowledge of the area.

This article presents an innovative one-page clinical teaching guide. Both instructors and students found that the guide was helpful in promoting personally meaningful learning outcomes. It was modifiable when applied in different psychiatric clinical settings and thought-provoking during an introductory mental health rotation. The work, grounded in a constructivist, student-centered epistemology, employed qualitative outcome analysis methodology and incorporated findings from a previous or base project as well as published work from educational researchers.

The purpose of the study was to work collaboratively with teachers and their students to create, test and refine a useful guide for nurses beginning to teach psychiatric nursing. The research extended four theoretical components derived from a base project that applied personal construct psychology in a case study design to examine how student nurses learn in the psychiatric clinical area. The aim of the guide, modified in the present study by the participating teachers and students themselves, was to identify practical assessment questions, to describe behavioural signs that demonstrated meaningful learning outcomes and to suggest relevant teaching strategies.

Two key areas of research are pertinent to this study clinical teaching in psychiatric mental health nursing and 
qualitative outcome analysis (QOA). A constructivist theoretical framework undergirds the project. A constructivist approach to research is a view that sees the participant not as a passive subject, but as an active co-creator of knowledge and emphasizes that observers are included in the domain of the observed, and that the focus is on process and pattern (Novak \& Gowin 1984, Candy 1989, Novak 1993, Peters 2000). QOA methodology extends readily from a constructivist worldview and lends itself to exploration and enquiry in complex interactive situations. This article describes the research approach, presents the guide as Table 1 and emphasizes practical instructional assessments and strategies in a discussion of the findings.

Although Gaberson \& Oermann (1999) provided a strong introduction to clinical teaching, a serious lack of current, practical, research-based guidance for instruction specific to the psychiatric area exists in published scholarly works addressing nursing education. Limited available research provided classic but dated or anecdotal suggestions (Gelfand \& Ullmann 1961, Morris 1964, Lewis \& Cleveland 1966, Holmes et al. 1975, Creech 1977, Marley
1980, Schoffstall 1981, Krikorian \& Pavlanka 1984, Yonge \& Hurtig 1987, Bairan \& Farnsworth 1989), emphasized disinterest in psychiatric nursing (Arnswald 1987, Perese 1996), highlighted contrasts with general nursing (Moir \& Abraham 1996, Wells \& McElwee 2000) and reflected an immediate need to explore creative teaching strategies that invite students to understand the area more deeply (Rushworth \& Happell 1998, Mohr \& Naylor 1999, Taymore 1999, Armstrong \& Pieranunzi 2000).

While it is clear that engaging student interest in the field of psychiatric nursing poses a longstanding challenge, instructors today also face the additional hurdle of a restructured workplace. In response to a paradigm shift in both nursing education and health care delivery, Canadian clinical teachers may be employed only on a short-term contract basis and by more than one employer. They can be required to orient to new curricula and clinical surroundings frequently and may not be involved in course planning decisions. Researchers exploring the nature of the teaching role acknowledged that limited support and direction is available to clinical nursing instructors (Crotty 1993,

Table 1

A clinical teaching guide for psychiatric mental health nursing

\begin{tabular}{|c|c|c|c|}
\hline Theoretical components & Assessment questions & (Student) behavioural signs & (Teaching) strategies \\
\hline $\begin{array}{l}\text { ONE } \\
\text { Understanding psychiatric } \\
\text { mental health nursing } \\
\text { is a personal process }\end{array}$ & $\begin{array}{l}\text { Does the learner believe } \\
\text { that mental health } \\
\text { concepts are relevant? }\end{array}$ & $\begin{array}{l}\text { Express links between course } \\
\text { concepts and personal interests } \\
\text { Discuss the process of making } \\
\text { connections between concepts } \\
\text { and intended area of practice }\end{array}$ & $\begin{array}{l}\text { Co-construct a personal learning- } \\
\text { plan with each student } \\
\text { Expect students to identify } \\
\text { personal learning in a weekly } \\
\text { reflective journal } \\
\text { Supply sample RN exam questions } \\
\text { Provide examples of excellent } \\
\text { student work }\end{array}$ \\
\hline $\begin{array}{l}\text { TWO } \\
\text { Feeling unsure about } \\
\text { how to help patients } \\
\text { provokes anxiety }\end{array}$ & $\begin{array}{l}\text { Can the learner articulate } \\
\text { relevant patient } \\
\text { outcomes such as those } \\
\text { stipulated in the course } \\
\text { curriculum? }\end{array}$ & $\begin{array}{l}\text { Identify common psychiatric disorders } \\
\text { Implement appropriate assessments } \\
\text { Demonstrate knowledge of } \\
\text { medications and other therapeutic } \\
\text { interventions } \\
\text { Report/chart concerns promptly } \\
\text { Individualize nursing care in } \\
\text { response to patient presentations } \\
\text { and agency milieu }\end{array}$ & $\begin{array}{l}\text { Invite unit staff and consumers } \\
\text { from local agencies as speakers } \\
\text { Provide concept maps, games, } \\
\text { puzzles and word matches, } \\
\text { etc. to supplement lecturel/text } \\
\text { Display information on agency } \\
\text { bulletin boards } \\
\text { Create files of newspaper and } \\
\text { magazine articles on mental } \\
\text { illness }\end{array}$ \\
\hline $\begin{array}{l}\text { THREE } \\
\text { Group involvement and } \\
\text { cohesion is highly } \\
\text { valued }\end{array}$ & $\begin{array}{l}\text { Is the learner an engaged } \\
\text { member of the clinical } \\
\text { group? }\end{array}$ & $\begin{array}{l}\text { Contribute ideas for climate-setting } \\
\text { Attend to peer needs and group } \\
\text { process }\end{array}$ & $\begin{array}{l}\text { Generate group 'rules' } \\
\text { Initiate optional student phone } \\
\text { support lists } \\
\text { Establish peer learning partners } \\
\text { Facilitate opportunities for } \\
\text { students to role-play their } \\
\text { own patients }\end{array}$ \\
\hline $\begin{array}{l}\text { FOUR } \\
\text { Non-evaluated } \\
\text { discussion time with } \\
\text { instructors is essential }\end{array}$ & $\begin{array}{l}\text { Does the learner view } \\
\text { instructors/perceptors as } \\
\text { both mentors and } \\
\text { evaluators? }\end{array}$ & $\begin{array}{l}\text { Initiate conversation about } \\
\text { meaningful learning achievements } \\
\text { or problems }\end{array}$ & $\begin{array}{l}\text { Phone each student before the } \\
\text { course starts } \\
\text { Post sign-up sheets for talk-time } \\
\text { appointments } \\
\text { Emphasize balanced self-evaluation } \\
\text { Frame evaluative comments } \\
\text { positively } \\
\text { Close the course with } \\
\text { unanswered questions }\end{array}$ \\
\hline
\end{tabular}


Owen 1993, Ferguson 1996, Forrest et al. 1996). Thus, using qualitative outcome analysis to create, test and refine a practical and concise teaching guide for novice instructors in the psychiatric clinical area is timely. This project makes three significant contributions. First, it responds to the current need for lively curricular innovations to promote interest in the specialty. Second, it transfers ideas about engagement and involvement generated from students themselves directly into theoretical components, assessment questions, behavioural signs and instructional strategies that promote personally meaningful learning outcomes. Third, it organizes relevant educational research to provide explicit direction to new instructors in a way that would not otherwise be available to them. The next section explains the research approach.

\section{The research approach}

This research applied a particular method of developing guides that applied qualitative research findings from a previous, or base project to practice (Morse et al. 1998, 2000, Morse 1999). The theoretical basis of the work stemmed from a constructivist conceptual perspective. Cresswell (1998) described a constructivist perspective as one that incorporates an emerging design, a context-dependent enquiry and inductive data analysis. Rooted in a client- or student-centred worldview and context, QOA methodology is a practical applied outcome-oriented approach that seeks to translate theory generated from research directly into the practice arena. Morse et al. (1998) assert that developing a guide permits interpretation of (student) behaviour and provides appropriate (in this case psychiatric) specialty knowledge and (in this case introductory) stage-specific teaching strategies. Morse et al. (2000) further explain that QOA is used to: 'confirm the efficacy of interventions when the experience changes over time, to extend the repertoire of intervention strategies and to further the clinician's understanding of possible outcomes' (p25). It is beyond the scope of this paper to elaborate on either the base project or the entire process of developing a guide. Essentially, descriptive qualitative theory derived from a base project, in this case Melrose (1998) and Melrose \& Shapiro (1999), is deconstructed to form the theoretical components. Assessment questions and behavioural signs are then elicited from the theory. Intervention strategies are extrapolated both from theory and from clinical teaching knowledge. Finally, the guide is implemented and tested using techniques of QOA to modify the guide and expand the repertoire of strategies.

In this project, the technique of QOA was collaborative writing and 1-hour long audio-tape recorded and transcribed interviews. The participants were six contract instructors (with limited teaching experience) and six of their students. The instructors implemented suggestions that they thought would be useful from an original guide drafted by the researcher. Both instructors and students tested and provided feedback on the ideas and the guide was re-constructed. The course was a required second-year psychiatric clinical practicum in a Canadian Baccalaureate programme. The practicum involved two 7-hour shifts each week for 7 weeks on an acute psychiatric placement. Participants in this study were not taught, evaluated or supervised by the researcher and represented inpatient units and outpatient programmes associated with three different urban hospitals and one rural provincial mental institution. Ethical approval was obtained from two Research Ethics Boards. In addition to the 12 designated interviews with key informants, extensive support and explanation was provided to all participants in person and by telephone before, during and after the course. All the resources required to implement the instructional strategies were provided by the researcher. The one-page guide was refined collaboratively during extensive discussions with the 12 participants. As participants' suggestions were incorporated and the changes made, the modified guide was re-written and circulated among the teachers and students. This ongoing verbal and written interaction and member-checking verified and confirmed the trustworthiness and authenticity of the work. The QOA aspect of the study spanned 6 months. Given that the theoretical findings from the 3-year base project emphasized a studentcentred context and perspective and were generated entirely from a group of student nurses, it was logical to test and refine the guide created in the present study by including a population of students once again. Morse $\mathrm{et} \mathrm{al}$. (1998) suggested that researchers obtain data from clients/ students in the setting to evaluate the guide, its components and the efficacy of the selected interventions. Evaluating and modifying the guide and interventions with participants by using QOA, and then disseminating the results, bridges the gap between theory and practice, extends the theory and expands the repertoire of research-based strategies (Morse et al. 2000).

Evaluating whether ideas from the base project made sense and had clinical relevance as theoretical components included questioning whether the work demonstrated Morse et al.'s (1998) criteria of theoretical appropriateness, adequacy and structure. Participants in both studies expressed that the four theoretical components were a 'fit' and relevant (appropriateness) and that they 'worked' and could be modified (adequacy). Participants in the present study commented that the structure of the final draft of the guide was systematic. Several commented on the simplicity of the linkages. A recurring theme that also emerged time 
and again during analysis of participants' audio-tape recorded interviews was that the project had been thoughtprovoking. It is important to emphasize that, even though points presented in the guide may be known implicitly to experienced faculty, the information is not readily available to novice clinical teachers and a QOA framework has not yet been used to extend case study research, or in nurse education. Essentially, testing the efficacy of this guide served as both a research and a pedagogical tool - and the following discussion of the teaching guide explains this dual purpose.

\section{The teaching guide}

The guide tested in this research offers a fresh look at the pedagogy of clinical teaching and learning. The format used to organize and present the information followed a four-step template for constructing assessment guides illustrated in Morse et al. (1998). The first step was identifying theoretical components. The second step was preparing assessment questions. The third step was identifying (student) behavioural signs. The fourth step was selecting (teaching) strategies. The theoretical components reflect students' real-world experiences and drive the guide. The assessment questions were constructed to sensitize and invite further discussion rather than simply to request a forced choice of 'yes' or 'no'. The behavioural signs were created to be specific and useful indicators of student learning and they illustrate answers to the assessment questions. The teaching strategies were clear, concise actions that combine theoretical deduction and expert nursing education knowledge. This section uses the four theoretical components to frame a discussion of participants' contributions as they tested and refined the guide.

\section{Theoretical component one: understanding psychiatric mental health nursing is a personal process}

Findings from the base project (Melrose 1998) concluded that student nurses learn about and come to understand psychiatric nursing in a very personal way. Given that the specialty can be perceived as unique, it is not unexpected that learners initially view the area as separate from their intended practice areas in mainstream nursing. Thus, articulating the individual processes that students employ to actively create their own personal connections to psychiatric mental health concepts is essential.

\section{Assessment question}

Actively involving students in a personal way is an established pedagogical principle. In the field of higher education, leaders committed to providing excellent instruction to university students agree that strategies to engage and include students must be planned with the same attention and energy academics devote to research activities (McKeachie 1986, Ramsden 1992, Davis 1993, Johnson 1995). In nursing education, Tanner (1997) equated the importance of involving students in their learning with the fundamental nursing principle of encouraging patients to ambulate postoperatively. However, assessing learner involvement in a specialized field is complex. In this study, participants agreed that the assessment question: 'Does the learner believe that mental health concepts are relevant?' effectively opened a dialogue about personal learning between clinical teachers and students.

\section{Behavioural signs}

Links between course concepts and personal interests. Participants in the present study confirmed that the following two behavioural signs would indicate that a process of active personal learning had been initiated. First, students would 'Express links between course concepts and personal interests'. Without exception, during the research interviews, each student participant described a family member, friend or acquaintance that struggled with a mental health issue. Students valued opportunities where they could express how they were creating links between these familiar experiences and the new and unfamiliar course concepts. Instructor participants described how students learned from one another when these links were articulated during conferences.

The process of making connections between concepts and intended area of practice.

Second, students would 'Discuss (their) process of making connections between concepts and intended area of practice'. When this behavioural sign was presented as an expected outcome, instructors commented favourably on the depth of student responses. One student, who intended to practice in the area of emergency nursing, created a set of index cards summarizing characteristics of psychiatric illnesses she might encounter in an emergency room. Another student, who intended to practice in obstetrics, gathered information about postpartum depression. Students found this behavioural sign particularly helpful in that it provided them with a personal way of constructing meaning within the field of psychiatric nursing.

\section{Instructional strategies}

\section{Co-construct a personal learning plan.}

A prominent feature of both the base project and the present study was the importance that student nurses 
placed on acknowledging personal learning. The first instructional strategy, 'Co-construct a personal learning plan with each student', was well-received by student participants. Although some instructors perceived that this strategy would be time-consuming and chose not to implement it, those who did so found it invaluable. A personal learning plan can readily be structured around the teaching guide presented as Table 1 . Throughout the rotation, students simply wrote out how they used the first assessment question to identify mental health concepts that were personally relevant, how they expressed links between course concepts and personal interests, and finally, how they made connections between these concepts and their intended area of practice. The students and instructors who chose to coconstruct a personal learning plan to supplement required curricular objectives found that the strategy provided a useful measurement of personal learning. One student commented: 'It helped make evaluation in this subjective rotation fair.

\section{Learning journals.}

Learning journals can enhance the clinical practicum experience (Landeen et al. 1992, Patton et al. 1997). The second instructional strategy, 'Expect students to identify personal learning in a weekly reflective journal', provided an opportunity to incorporate the personal learning plan described above into a learning journal. Several student participants in this study supplemented their required journal assignment with a personal learning plan. According to one student: 'Without trying this I might not have done much extra work in this course. A lot of students just call psych the "ping-pong and cards rotation", but I liked using the time to find out the things I need to know when mental health comes up in paediatrics - that's where I'm going to work'. An instructor commented: 'It's easier to see how students are actually integrating clinical knowledge with these personal learning plans'.

\section{Exam questions.}

The third instructional strategy, 'Supply sample RN exam questions', was considered important by students and easy to implement by instructors. Davis (1993) and Johnson (1995) advocate providing university students with sample exam questions early in their courses. In the psychiatric clinical area, nursing students may not be given written examinations, but will write professional licensing examinations at the end of their programme of study. Highlighting test questions from examination preparation books such as the Canadian RN Exam Prep Guide (Canadian Nurses Association 2000) provided students with examples of questions related to psychiatric nursing.
Examples of student work.

Similarly, the fifth strategy, 'Provide examples of excellent student work', was valued by students and easy to implement by instructors. Obtaining student permission to copy exemplary assignments students constructed and sharing them with fellow students and even staff members was useful. Elbow (1986) encouraged instructors in higher education to design assignments that would be read by peers. Student participants in this study felt that they learned from the content of their peers' assignments as well as the process other students engaged in as they completed the task. Agency staff, particularly those new to the area, also sincerely appreciated reading students' work and gained a deeper understanding of the students' clinical objectives. One student remarked: 'I do a better job with an assignment if I think that somebody besides my instructor will read it'.

\section{Theoretical component two: feeling unsure about how to help patients provokes anxiety}

Student narrative from the base project (Melrose 1998) indicated that student nurses felt anxious about their ability to help psychiatric patients. This finding was not unexpected and was consistent with existing studies. Arnold \& Nieswiadomy (1997) provided a useful preclinical exercise to begin to address this issue. However, none of the contract instructors who participated in the present study felt that they had sufficient training or experience with teaching methods to deal adequately with students' essential need to know about what to 'do' for their patients. While the assessment question and behavioural signs in this section were considered useful guideposts to students, they offered only nominal direction to instructors. However, participants all agreed that the instructional strategies did help to reduce anxiety, to entice students to explore available knowledge and, ultimately, to construct their own ideas about how best to help their patients.

\section{Assessment question}

It is important to reiterate that the guide presented in this paper was designed as a supplement to enhance the existing curriculum. Clearly, the most important assessment questions clinical instructors pose is whether students can articulate relevant patient outcomes in relation to the objectives and evaluation criteria stipulated in course guidelines. Thus, participants agreed that the assessment question, 'Can the learner articulate the relevant patient outcomes stipulated in the course curriculum?', offered useful direction. 


\section{Behavioural signs}

Participants found that the following five behavioural signs were adequate indications that a student was able to help patients in the psychiatric mental health area:

- Identify common psychiatric disorders

- Implement appropriate assessments

- Demonstrate knowledge of medications and other therapeutic interventions

- Report/chart concerns promptly

- Individualize nursing care in response to patient presentations and agency milieu.

\section{Instructional strategies}

\section{Guest speakers.}

The instructional strategies presented in this section were considered helpful. Participants all believed that the first strategy, 'Invite unit staff and consumers (of mental health services) from local agencies as speakers', stimulated discussions about important nursing care. Students, particularly those with a predominantly auditory style of learning, valued a brief 'Welcome Talk' from their agency placement manager and opportunities when practitioners joined the student group to describe specific psychiatric nursing interventions. Community mental health agencies often have a 'Speakers Bureau' where individuals recovering from mental illness carry out volunteer speaking engagements with interested groups. At the end of the course, the students in this study expressed that these speakers had made a strong and positive impression on their learning. A similar strategy, which also emphasizes the experience of mental illness from a patient-centred perspective, is to make available memoir books about authors' own experiences with mental illness. Sayre (2001) described a method of using personal accounts of mental illness as a teaching tool and recommended 32 relevant books.

\section{Activities to supplement course requirements.}

By count, it was the second strategy, 'Provide concept maps, games, puzzles and word matches, etc. to supplement lectures/texts', which participants found the most helpful and thought-provoking. Once instructors introduced playful ways of organizing course information, students followed suit and risked constructing their own methods of categorizing psychiatric mental health nursing concepts. The games and activities are not included in this paper but can be obtained by contacting the researcher.

Concept maps are graphic organizers (Novak \& Gowin 1984, Baugh \& Mellot 1998, Daley et al. 1999). Ideas can be arranged visually to show the connections between and among concepts as they are studied. Inspiration (2000) software offers useful templates for creating maps.
Puzzles, inspired by Poston (1998), were constructed from an inexpensive computer program from Expert (1997) software entitled 'Crosswords and Word Games'. Basic psychiatric vocabulary was introduced into the program and puzzles were easily generated.

Word matches, i.e. linking a word to a definition, were computer-generated in this study, but could also be done using two simple columns. The process of working through the games, puzzles and word matches stimulated lively discussions. One participating instructor described another game where she brought in finger paints and invited students to express their feelings about the rotation through this medium. Another instructor brought in recycled glossy magazines, glue sticks and scissors for students to construct a collage. These strategies appealed to students with a kinesthetic learning style.

\section{Bulletin boards.}

The third strategy was: 'Display information on agency bulletin boards'. Elementary school classrooms generally have enticing and colourful displays of information on bulletin boards. In higher education settings or health care practicum sites, bulletin boards are also sources of information, but they are seldom arranged or decorated systematically. Instructors in this study found that requesting space on agency bulletin boards was an efficient method of communicating course material. This strategy appealed to visual learners and created another link between university curricula and the practicum site.

\section{Articles.}

The fourth strategy, 'Create files of newspaper and magazine articles on mental illness', was also supplied by the researcher. Although none of the novice instructors in this study had yet developed a collection of non-professional articles, they expressed interest in maintaining their own ongoing and accessible files of newspaper and magazine articles related to mental illness at their practicum sites. The collection could include contributions from both practitioners and students. Students commented that this genre was easier and more stimulating to read than journal articles. During pre- and postconferences, instructors facilitated discussion around the differences and similarities between popular and professional literature. Focus issues included how sensationalist writing can intensify the stigma associated with mental illness. Students found it intriguing to talk about what it might be like to write different kinds of articles, and instructors encouraged students to view themselves as authors instead of simply readers. 
Teaching assignments.

The fifth strategy was, 'Assign students to teach psychiatric conditions to patients, peers or auxiliary staff'. Student nurses are often expected to teach patients about their illness and prescribed medications. A variation on this established practice is to direct students to teach a younger or more junior student, an auxiliary staff member, or a member of the public about a mental illness or treatment. The process of translating professional jargon into everyday language can be an effective way of understanding new ideas and terms.

\section{Theoretical component three: group involvement and cohesion is highly valued}

Student nurses consistently expressed a strong need for involvement with their clinical group throughout both projects. Instructors also expressed a commitment to creating cohesion within their student groups. The guide served as a reminder of the importance of fostering group involvement and stimulating awareness of group process and team building.

\section{Assessment question}

Participants found that posing the question, 'Is the learner an engaged member of the group?', did begin a process of sharing group maintenance tasks among students. The question prompted discussions related to group dynamics and norms, the roles that members and leaders assume in groups, and stages of group growth.

\section{Behavioural signs}

Student participants, in particular, reported that the following two behavioural signs provided them with a clear indication that they were expected to take responsibility for climate-setting and group process within their psychiatric mental health clinical group:

Contribute ideas for climate setting

Attend to peer needs and group process.

\section{Instructional strategies}

\section{Ground rules.}

The first instructional strategy, 'Generate group "rules", was well known to all the instructors who participated in the present study. It was surprising to note, however, that none of these instructors had considered using the strategy with their student group. Again, the one-page guide served as a prompt to discuss the merit of creating a safe group learning environment for students during this rotation. Students appreciated generating ground rules and one student remarked: 'It's good to see how nurses are supposed to lead groups. We're taught about "facilitating”, but I like actually seeing it done.' Examples of ground rules generated in this study included an expectation of confidentiality, respectful communication and the right and responsibility to participate in different ways. Snyder \& Weyer (2000) encouraged affording 'more time ... to attend to group roles and process' (p319) during clinical experiences.

\section{Optional phone support lists.}

The second instructional strategy, 'Initiate optional student phone support lists', was welcomed by students and was simple to initiate for instructors. Given the essential need to respect privacy, participants discussed the point that any disclosure of phone numbers or contact information must remain optional.

\section{Peer learning partners.}

Encouraged by the success of Goldenberg \& Iwasiw's (1992) experience with reciprocal or peer/collaborative learning during a medical surgical rotation, the idea of learning partners was incorporated into the present teaching guide as the third strategy. Although some instructors were not interested in this strategy, those who did create student learning partnerships clearly found the practice useful. Students who worked in partnerships were unanimous in their agreement that the experience was a highlight of their learning. At the beginning of the rotation, instructors assigned each student to a partnership. In the case of an uneven number of students in a clinical group, a dyad was modified to a triad. Within the partnership, students completed the puzzles together, double-checked one another's medication knowledge and were encouraged to actively listen to each other throughout the clinical experience. According to one student: 'It really helped to talk about my own feelings with my learning partner. I might not have felt as comfortable to do that if it wasn't set up like this.'

Role-play.

The fourth strategy, 'Facilitate opportunities for students to role play their own patients', was considered nominally useful. Instructors agreed that the strategy seemed more appropriate toward the end of the rotation. Student reaction was mixed in that some students enjoyed role-play, while others did not. However, even students who felt reluctant to participate, chose to include the strategy in the final presentation of the guide.

\section{Theoretical component four: non-evaluated discussion time with instructors is essential}

Time and again throughout the base project (Melrose 1998), students emphasized the benefit of non-evaluated 
discussion time with their instructors. Similarly, students in the present QOA study made frequent reference to individual conversations with their clinical teachers.

\section{Assessment question}

Performance evaluation considerations can dominate a clinical experience for students and novice instructors. However, clinical teachers are also expected to mentor their students. The assessment question, 'Does the learner view instructors/preceptors as both mentors and evaluators?', was useful in emphasizing that tasks of mentoring, as well as evaluating, are inherent within the clinical teaching role.

\section{Behavioural signs}

Participants agreed that the behavioural sign, 'Initiate conversation about meaningful learning achievements or problems', invited students to share their own constructions of knowledge.

\section{Instructional strategies}

The strategies participants agreed should be presented in this section could easily be overlooked. However, gestures such as: 'Phone each student before the course starts', and, 'Post sign up sheets for talk-time appointments', created a positive impression with students. Also, learner strengths were supported through strategies such as 'Emphasize balanced self-evaluation', and 'Frame evaluative comments positively'.

Given the complex nature of psychiatric nursing, it is not unexpected that an introductory clinical course in the field leaves students with many unanswered questions. In addition to honouring students for the competency knowledge they demonstrated in relation to their course objectives, and the individual knowledge they constructed in relation to their personal learning plans, it was helpful to recognize that unknown knowledge also exists. The final strategy, 'Close the course with unanswered questions', addressed this issue. Linking back to the process students in this research used to connect their psychiatric clinical experience to an intended area of practice, the strategy of inviting unanswered questions was considered appealing. For example, a student who hoped to work in pediatrics commented: 'My unanswered question is about the difference between some children's inappropriate behaviour and an actual psychiatric illness.' Another student left the rotation thinking more deeply about the issue of recidivism. One instructor viewed the strategy as 'a relief - I can't possibly set up opportunities for everything.'

\section{Conclusion}

The teaching guide presented in this article was created and tested by students and instructors in the psychiatric mental health clinical area. The qualitative outcome analysis research approach used in this project was unique in that the methodology applied theoretical findings from a previous naturalistic study directly into clinical teaching practice. The process of testing the efficacy of the guide served as a pedagogical tool for novice instructors and made implicit knowledge about clinical teaching methods more explicit. The guide extends existing nursing education knowledge by creating useful and thought-provoking assessment questions, behavioural signs and instructional strategies from learner-centred theoretical components. The work emphasizes a continuing need to explore clinical teaching strategies that engage students, sustain their involvement and invite them to construct personally meaningful knowledge. Readers are invited to continue testing the merit of the guide and to extend their repertoire of strategies.

\section{References}

Armstrong M. \& Pieranunzi V. (2000) Interactive approaches to teaching/learning in the psychiatric mental health practicum. Journal of Nursing Education 39, 274-277.

Arnold W. \& Nieswiadomy R. (1997) A structured communication exercise to reduce nursing students' anxiety prior to entering the psychiatric setting. Journal of Nursing Education $36,446-447$.

Arnswald L. (1987) Not fade away. Journal of Psychosocial Nursing 25, 31-33.

Bairan A. \& Farnsworth B. (1989) Attitudes toward mental illness: does a psychiatric course make a difference? Archives of Psychiatric Nursing 111, 351-357.

Baugh N. \& Mellott K. (1998) Clinical concept mapping as preparation for student nurses' clinical experiences. Journal of Nursing Education 37, 253-256.

Canadian Nurses Association (2000) The Canadian RN Exam Prep Guide, 3rd edn. Canadian Nurses Association, Ottawa, Canada.

Candy P. (1989) Constructivism and the study of self-direction in adult learning. Studies in the Education of Adults 21, 95-116.

Creech S. (1977) Changes in attitude about mental illness among nursing students following a psychiatric affiliation. Journal of Psychosocial Nursing and Mental Health Services 15, 9-14.

Cresswell J. (1998) Qualitative Inquiry and Research Design: Choosing Among Five Traditions. Sage Publications, Thousand Oaks, CA.

Crotty M. (1993) The changing role of the nurse teacher. Nurse Education Today 13, 416-420.

Daley B., Shaw C., Balistrieri T., Glasenapp K. \& Piacentine L. (1999) Concept maps: a strategy to teach and evaluate critical thinking. Journal of Nursing Education 38, 42-47.

Davis B.G. (1993) Tools for Teaching. Jossey-Bass, San Francisco.

Elbow P. (1986) Embracing Contraries. Oxford University Press, New York.

Expert (1997) Crossword and Word Games [Computer software]. Coral Gables, FL. 
Ferguson D.S. (1996) The lived experience of clinical educators. Journal of Advanced Nursing 23, 835-841.

Forrest S., Brown N. \& Pollock L. (1996) The clinical role of the nurse teacher: an exploratory study of the nurse teacher's present and ideal role in the clinical area. Journal of Advanced Nursing 24, 1257-1264.

Gaberson K. \& Oermann M. (1999) Clinical Teaching Strategies in Nursing. Springer Publishing, New York.

Gelfand S. \& Ullmann L. (1961) Attitude changes associated with a psychiatric affiliation. Nursing Research 8, 201-203.

Goldenberg D. \& Iwasiw C. (1992) Reciprocal learning among students in the clinical area. Nurse Educator 17, 27-29.

Holmes G., Klein L., Stout A. \& Rosenkranz A. (1975) Nursing students' attitude toward psychiatric patients. Journal of Psychosocial Nursing and Mental Health Services 13, 6-10.

Inspiration (2000) The Premier Tool to Develop Ideas and Organize Thinking (Version 6) [Computer Software]. Inspiration Software, Portland OR. (http://www.inspiration.com)

Johnson G. (1995) First Steps to Excellence in College Teaching, 3rd edn. Magna Publications, Madison, WI.

Krikorian D. \& Pavlanka B. (1984) Students' perception of learning and change in the psychiatric clinical setting. Perspectives in Psychiatric Care 22, 118-124.

Landeen J., Byrne C. \& Brown B. (1992) Journal keeping as an educational strategy in teaching psychiatric nursing. Journal of Advanced Nursing 17, 347-355.

Lewis I. \& Cleveland S. (1966) Nursing students' attitudinal changes following a psychiatric affiliation. Journal of Psychiatric Nursing 4, 231-233.

Marley M. (1980) Teaching and learning in a psychiatric mental health setting. Journal of Psychosocial Nursing and Mental Health Services 18, 16-21.

McKeachie W. (1986) Teaching Tips, 8th edn. Heath, Lexington, MA.

Melrose S. (1998) An exploration of students' personal constructs: implications for clinical teaching in psychiatric mental health nursing. Unpublished PhD Dissertation, University of Calgary, Calgary, Alberta, Canada.

Melrose S. \& Shapiro B. (1999) Students' perceptions of their psychiatric mental health clinical nursing experience: a personal construct theory exploration. Journal of Advanced Nursing 30, 1451-1458.

Mohr W. \& Naylor M. (1999) Breaking through the hegemony of homogeneity: revitalizing curriculum and students. Journal of Nursing Education 38, 28-32.

Moir J. \& Abraham C. (1996) Why I want to be a psychiatric nurse: constructing an identity through contrasts with general nursing. Journal of Advanced Nursing 23, 295-298.

Morris K. (1964) Behavioral change: a concomitant of attitude change in nursing students. Nursing Research 13, 132-138.

Morse J. (1999) Assessing and evaluating qualitative research. Post-conference workshop presented at the International Nursing Research Conference, Edmonton, Canada.
Morse J., Hutchinson. S. \& Penrod J. (1998) From theory to practice: the development of assessment guides from qualitatively derived theory. Qualitative Health Research 8, 329340.

Morse J., Penrod J. \& Hupcey J. (2000) Qualitative outcome analysis: evaluating nursing interventions for complex clinical phenomena. Journal of Nursing Scholarship 32, 125-130.

Novak J. (1993) Human constructivism: a unification of psychological and epistemological phenomena in meaning making. International Journal of Personal Construct Psychology 6, 167-193.

Novak J. \& Gowin D. (1984). Learning How to Learn. Cambridge University Press, New York.

Owen S. (1993) Identifying a role for the nurse teacher in the clinical area. Journal of Advanced Nursing 18, 816-825.

Patton J.G., Woods S.J., Agarenzo T., Brubaker C., Metcalf T. \& Sherrer L. (1997) Enhancing the clinical practicum experience through journal writing. Journal of Nursing Education 36, 238-240.

Perese E. (1996) Undergraduates' perceptions of their psychiatric practicum: positive and negative factors in inpatient and community experiences. Journal of Nursing Education 35, 281284.

Peters M. (2000) Does constructivist epistemology have a place in nurse education? Journal of Nursing Education 39, 166-172.

Poston I. (1998) Crossword puzzles: adjunct clinical strategy. Journal of Nursing Education 37, 266-267.

Ramsden P. (1992) Learning to Teach in Higher Education. Routledge, London.

Rushworth L. \& Happell B. (1998) Psychiatric nursing education: doing the impossible. Archives of Psychiatric Nursing 12, 319-325.

Sayre J. (2001) Using personal accounts of mental illness as a teaching tool. Journal of Nursing Education 40, 93-95.

Schoffstall C. (1981) Concerns of student nurses prior to psychiatric nursing experience: an assessment and intervention technique. Journal of Psychosocial Nursing and Mental Health Services 19, 11-14.

Snyder M. \& Weyer M. (2000) Baccalaureate nursing students' reflections on a nontraditional mental health experience: learning outcomes. Journal of Nursing Education 39, 318-319.

Tanner C. (1997) Teaching is a practice. Journal of Nursing Education 36, 306-307.

Taymore K. (1999) Characteristics of the psychiatric clinical nursing laboratory in the state of Arkansas. Journal of Nursing Education 38, 360-363.

Wells J. \& McElwee C. (2000) The recruitment crisis in nursing: placing Irish psychiatric nursing in context - a review. Journal of Advanced Nursing 32, 10-18.

Yonge O. \& Hurtig W. (1987) Student-identified factors which facilitated learning in a six-week psychiatric nursing rotation. Canadian Journal of Psychiatric Nursing 28, 12-14. 